Contemporary Social Science

Journal of the Academy of Social Sciences

\title{
Imagining the future in a difficult present: storylines from Spanish youth
}

\section{María Luz Morán \& Laura Fernández de Mosteyrín}

To cite this article: María Luz Morán \& Laura Fernández de Mosteyrín (2017): Imagining the future in a difficult present: storylines from Spanish youth, Contemporary Social Science, DOI: 10.1080/21582041.2017.1372620

To link to this article: http://dx.doi.org/10.1080/21582041.2017.1372620

Published online: 13 Sep 2017.

Submit your article to this journal $\sqsubset$

Q View related articles

View Crossmark data [ 


\title{
Imagining the future in a difficult present: storylines from Spanish youth
}

\author{
María Luz Morán (D) a and Laura Fernández de Mosteyrín (D) b \\ ${ }^{a}$ Department of Sociology I (Social Change), Universidad Complutense de Madrid, Madrid, Spain; \\ bepartment of Criminology, Universidad a Distancia de Madrid, UDIMA, Madrid, Spain
}

\begin{abstract}
This paper examines Spanish juveniles' effort to imagine the future in times of uncertainty. The breakdown of youth strategies to adulthood exacerbates the disarticulation of imagined futures. 'Presentism' is further intensified by the 2008 crisis, making it difficult for youth to 'find their place in the world'. Our evidence comes from biographical narratives collected in the form of 'letters' written by Spanish university students. Borrowing from literature on youth transitions, temporal sociology and situated culture, we develop a narrative analysis which shows how, in the process of imagining their future, Spanish youth are reconsidering their expectations and generating new solutions. Their accounts show how they manage to connect their individual experiences with the collective, generational dimension.
\end{abstract}

ARTICLE HISTORY

Received 5 July 2017

Accepted 19 July 2017

KEYWORDS

Youth; future; narrative; crisis; Spain

\section{Introduction}

The aim of this article is to show how young Spaniards represent their future in a context characterised by a far-reaching economic, social and political crisis that has had a particularly marked impact upon them. ${ }^{1}$ This crisis, together with the imposition of a hegemonic discourse - an 'ideational regime' (Somers, 2008) - in relation to it has modified their transitions to adult life to the extent that many of the strategies that they had designed and implemented to culminate their socio-political integration have become obsolete in the course of just a few years.

On the basis of these premises, we develop three hypotheses. First and foremost, we consider that the breakdown suffered by the strategies of young people exacerbates the disarticulation of their imagined futures, something that has already been described in various studies on the consequences of the greater complexity of their transitions to adulthood and the acceleration of the rhythms of life. Second, the crisis increases tensions among young people when they seek their forward projection into the future to 'find their place in the world', so that they are forced to devise new stories about the possibilities, fears and hopes of adult life. Finally, although writing a piece about one's future is undoubtedly an individual endeavour, imagining the future is not. It is a relational process by which individuals establish a dialogue with others and with the broader cultural framework. According to Swidler, culture is imagined before it can be put to work:

CONTACT Laura Fernández de Mosteyrín lauramaria.fernandez@udima.es 